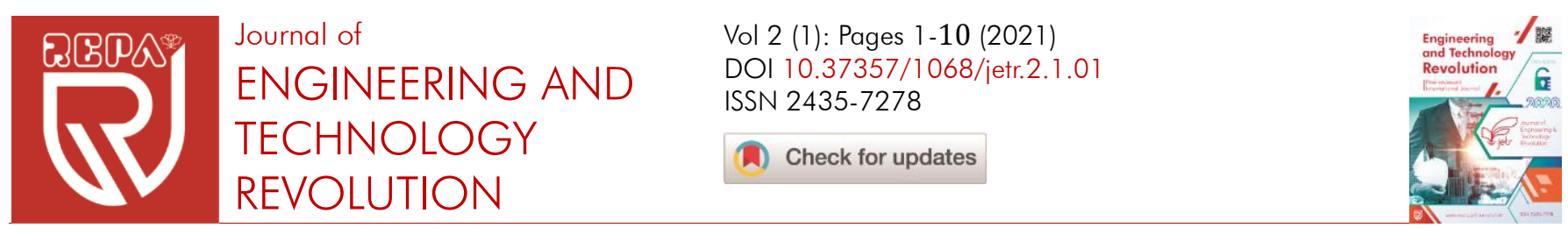

\title{
Developing nations as a foremost allotment for achieving 2030 SDGs
}

\section{A case study}

Mir Sayed Shah Danish ${ }^{1,2}$, Tomonobu Senjyu ${ }^{3}$, Naomitsu Urasaki ${ }^{3}$, Nisar Ahmad Rahmany², Ahmad Murtaza Ershad ${ }^{2}$, Najib Rahman Sabory², Ahmad Khaled Zarabie ${ }^{2}$, Mohammad Abed Anwarzai², Hedayatullah Karimy² and Hameedullah Zaheb $^{2}$

${ }^{1}$ Strategic Research Project Center, University of the Ryukyus, 1 Senbaru, Nishihara, Okinawa 9030213, Japan

${ }^{2}$ Department of Energy Engineering, Faculty of Engineering, Kabul University, Kabul 1006, Afghanistan

${ }^{3}$ Department of Electrical and Electronics Engineering, Faculty of Engineering, University of the Ryukyus, 1 Senbaru, Nishihara, Okinawa 903-0213, Japan

\section{Article}

Open Access
Published

Keywords

- Sustainable development goals (SDGs)

- Developing nations

- Rural empowerment

- Socio-economic development

- Micro-grid

- Circular economy

- Micro-economy theorem

- SDGs adoption

- Sustainable energy

\section{ABSTRACT}

Afghanistan endows enormous renewable and nonrenewable resources as a primary impetus for development of energy and agriculture. The percentage of the population whose access to the essential daily necessities for having a healthy life is among the lowest in the world. This dilemma chiefly refers to the rural and remote communities in Afghanistan. In terms of rural societies, sustainable development is a decision-making strategy that balances social, economic, technical, institutional, and environmental aspects that assures the present needs of humankind, considering the future anticipation simultaneously. The concept developed in this study targets achieving the 2030 sustainable development goals (SDGs), which are appropriate for rural and remote residents' lifestyle change and improvement in Afghanistan. Setting measurable sustainability indicators is indispensable for the productive invention of a sustained plane for a sustainable rural community. This study proposes a sustainable mechanism for Afghanistan's rural development by confirming the 2030 sustainable development 17 Goals (SDGs). Among these SDGs, the designed framework (methodology) meets 11 goals directly and the rest of 6 goals indirectly. Besides, the proposed framework propounds a novel solution and involves all crucial segments of routine healthy life in rural Afghanistan. It consecrated criteria that fit the real-life anticipations and can lead the rural communities toward self-sufficiency for long-run sustainability. Based on the academic research and experts' judgment methods, overall analysis procedures can fit as an analogy, especially for other communities and developing countries as a pilot project.

Received: July 20, 2021; Revised: August 10, 2021; Accepted: August 12, 2021; Published: August 20, 2021

(C)2021 REPA. All rights reserved.

\section{Introduction}

The 2030 agenda for sustainable development goals (SDGs) principally encompasses humanity and our planet challenges, consisting of 17 main goals and 169 sub-targets, unanimously adopted by the United Nations General Assembly on September 2015 [1]. For developed nations, implementing the GSDs 2030 and achieving target millstones would be an easy task. Whereas developing countries encounter knotty challenges to practice the GSDs 2030 milestones and attain the goals. Among these bottlenecks can remind few such as weak governance and management, lack of expertise and resources, inadequate national and international collaborations behavior,

From the vulnerability point of view, in the 21st century, the world becomes likely a small village. In which developed and developing nations directly affect each other, that necessitate a mutual liability. In this regard, by referring to the past, international assistance is definitely at the top list of the financial and technical support to Afghanistan. Because of the present situation of Afghanistan, thousands of rural communities in Afghanistan depend solely on traditional lifestyles and rarely have access to electricity, drinking water, and food for their routine. This study is conducted to offer real-life solutions to this problem. According to the National Solidarity Program (NSP), as of 2007, 42000 villages are referred to as rural settlements in Afghanistan [2]. According to [3], nearly $4 \%$ of rural households have access to electricity in Afghanistan. Over $20.4 \%$ of the rural population cannot meet the minimum level of dietary energy required to sustain a healthy life. According to the Ministry of Public Health [4] of Afghanistan, most cities suffer from poor air quality and overcrowding due to rural settlement in the big cities. That caused to rank the capital of Afghanistan (Kabul city) among the ten top dirtiest cities in the world [5].

On the other hand, countries are bounded by international agreements. The Paris Summit on climate change was put in action with a unanimous agreement of 195 signatories and 179 parties on 12 December 2015 at the twenty-first session of the Conference of the Parties to the UN (United Nations) (Officially registered on 4 November 2016, No. 54113). Afghanistan representative at the UN, signed this agreement on 22 April 2016 [6]. According to the [7], "The Paris Agreement central aim is to strengthen the global response to the threat of climate change by 


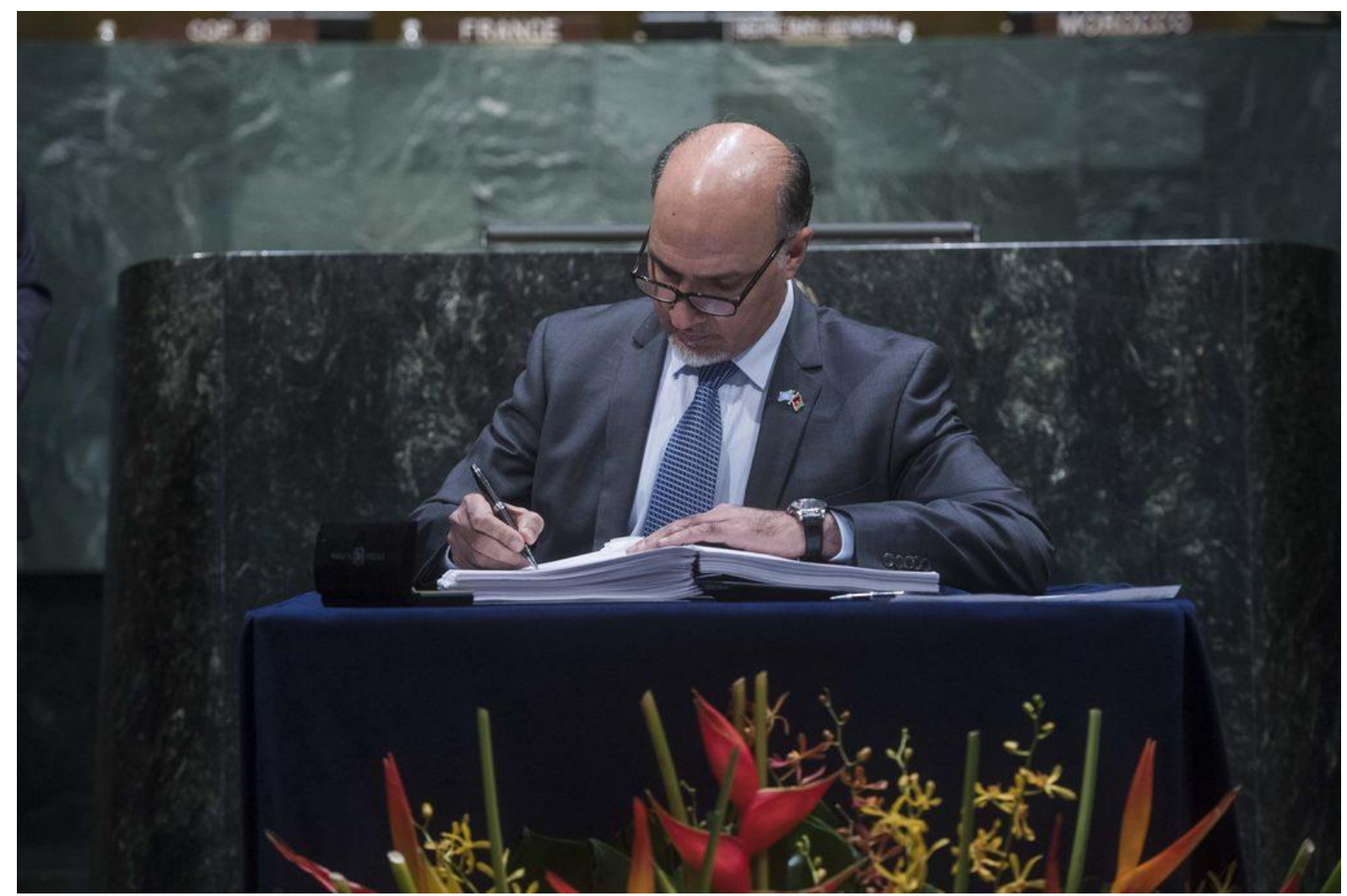

Figure 1. Mr. Mahmoud Saikal (Ambassador extraordinary and plenipotentiary permanent representative of the Islamic Republic of Afghanistan at the UN) signed the Paris Agreement on climate changes [8].

The Paris agreement assigns essential international responsibilities for ensuring a peaceful sound planet. In like manner, the 2030 Agenda for Sustainable Development Goals (SDGs) is another cross-boundary collaborative effort to be achieved. Although the accepted agreement that the world we live in is steadily polluting air and the greenhouse gas emissions continue in an umpteen quantity, renewable energy is the only hope for a sustainable energy resource for greenhouse gases free atmosphere. Based on the aforesaid global accountability, there are many opportunities to utilize, which are viable collaboration aims for developed and developing to combat climate change, and provide sustainable energy for socio-economic development in order to fulfill the international agreements.

\section{Objectives}

As a fact, raising expectations for self-sufficiency (at any pillar of socio-economic sustainability) beyond a doubt will increase the communities' attitude, capacity, and standard. It has known the key to meeting the goals, but inadequate long-term prospects turn into false hope. Authors in [2] indicate some points as lesson-learned to be cautious, which caused rural electrification project failure in Afghanistan due to an immature electrification policy. Referring to the world best practices, the concept of micro-development in sustainability would be very practical, requiring a multi-dimensional investigation of different scenarios to reach an optimum solution for long-run sustainability.

Overall, this effort aims to formulate an exhaustive framework for the socio-economic developments of Afghanistan's rural and remote communities. The proposed framework comprises five pillars of sustainability, including the 2030 SDGs, initiated based on the scientific theories, expert judgments, real-world lessons-learned (sample case studies around the world), and at last, a fixable and suitable model, particularly for Afghanistan to provide the follows facilities:

1- Twenty-four-hour reliable electricity supply for residential and public facilities

2- Drinking water supply and water purification

3- Water supply for agriculture (greenhouse)

4- Enhancing food security through the production of meat and egg by forming local farms

5- Ensuring equity between the rural and urban life

6- Building local capacity and empower human rights

7- Improving the socio-economic through creating temporary and permeant jobs 
8- At last, forming self-sufficiency by changing to a healthy lifestyle for long-run sustainability.

Sustainability adaption can be different from country to country and community to community in the same country due to social, cultural, environmental, institutional, political, geographical, economic, technical, and many more decisive factors. Therefore, for this model, pre-defined sustainability pillars are outlined as well.

\section{Methodology}

In rural society, sustainable development is a decisionmaking strategy that balances social, economic, technical, institutional, and environmental aspects, simultaneously considering present and future generations' needs $[9,10]$. Setting measurable sustainability indicators is indispensable for the efficacious invention of a sustained plane for a sustainable rural community. Today's cutting-edge renewable energy technologies should propound the sustainability culture at the rural community level and implement the necessary plans to achieve national and international sustainable goals. For instance, the European energy supply objectives $(20-20-20)$ by 2020 , where 20 stands for a reduction of $20 \%$ of greenhouse gas emissions, increasing energy efficiency by $20 \%$, and $20 \%$ production of electricity from renewable energy sources, compared to 1990 levels, respectively [11].

Among energy utilities, buildings consume a significant amount of energy that can be different based on energy consumption culture from country to country. Since Afghanistan is not an industrial country, the energy consumption is most likely residential. Buildings consume $40 \%$ of the total energy and emit $30 \%$ of greenhouse gas emissions (GHGs) worldwide [12]. There are some case studies [13-15] conducted for India, Chili, and Nicaragua, which are almost in conformance to the present situation of Afghanistan, that can be counted as a useful reference.

For proper planning for rural communities, the household characteristics must be collected through survey tools and techniques. These characteristics can contain much information, with at least some essentials as [1315]: number of households, land holdings, labor and demographic, gender percentage, ages, literacy percentage, number of educated residence, immigration information, infrastructures accessibility (paved road, dirt road, trail, hospital, etc.), access to energy, access to clean water, average household income, local expectations, available resources, transformable options, and many more. The abovementioned endeavors can be achieved in three main steps:

- Developing program concept

- Conducting feasibility studies

- Designing a sustainable solution
These steps consist of many sub-activities (Figure 2). This study solely concentrated on the conceptualization of an exhaustive framework within the SDGs scope.

\section{Call for global collaboration}

Although SDGs pertaining to the global contribution at the country-level, everyone (especially scholars and researchers) is liable to partake in these crucial trends to rescue our planet for current and future generations. This participation can take in various forms within a flexible mechanism at different levels of engagement. For this reason, we have resorted to initiating international collaborative efforts to assist developing countries in climate change. This collaboration will consist of direct and indirect engagements within a managed framework. Thriving the concept (as a pilot project) can attract further investment on the concept by national and international donors throughout the country. That offers a transparent process and cost-effective service for rural self-sufficiency. While at the present many national and international entities could not spend their targeted budgets for each fiscal year. Luckily, this concept covers various aspects that can be invested in many different budget lines. So, this concept can be applied to specific programs but also in the future. It can be counted as a roadmap for other assistance in this regard. There are many funds to cover such projects like science and technology research partnership for sustainable development (SATREPS) program by the government of Japan and many more that deal with global issues at the developing countries to improve societies' socio-economic status through joint researches of international communities for the sake of ensuring real-world implementation of the research's outcomes [1]. To prosecute the SDGs goals, the ultimate aim of such programs is to develop an innovative mechanism to resolve global issues through acquirement new knowledge and advancement of science and technology by enhancing partner countries' research and development capabilities.

Feasibility study of the SDGs (17 goals) of the targeted society to identify the socio-economic improvement opportunities and affordability in conformity with the current status. The initial objective of this feasibly is to reveal the exhaustiveness of the proposed mechanism and show how the mechanism can play a significant part of SDGs. It indicates the effectiveness of the proposed mechanism at national (for Afghanistan) and international levels for long-run sustainability.

\section{The proposed conceptual model}

Reference to the literature, it is important to form several standpoints to apply all sustainability pillars in the context of a sustainable rural community. Central to the entire discipline of the sustainable rural community is the concept of multi-dimension pillars to concur with every society's unique environmental, ecological, social, cultural, 
economic, institutional, political, and technological conditions. The proffered conceptual framework is a typical model that can be suitably modified case by case based on the actual needs of the communities (add or remove features and facilities), but at all the concept can be unique.

At this stage (concept development), the basic SWOT (strengths, weaknesses, opportunities, and threats) analysis planning tool is recommended to identify and compare the effectiveness of the proposed model. It is noteworthy that for further investigation, subtler tools and techniques will be applied, such as contingency analysis, root and cause analysis, risk and impact analysis and so on, at the following stages of assessment. The conceptual scheme for this program presents a big picture of anticipation, which each segment needs to be explored in detail from different perspectives (Figure 3).

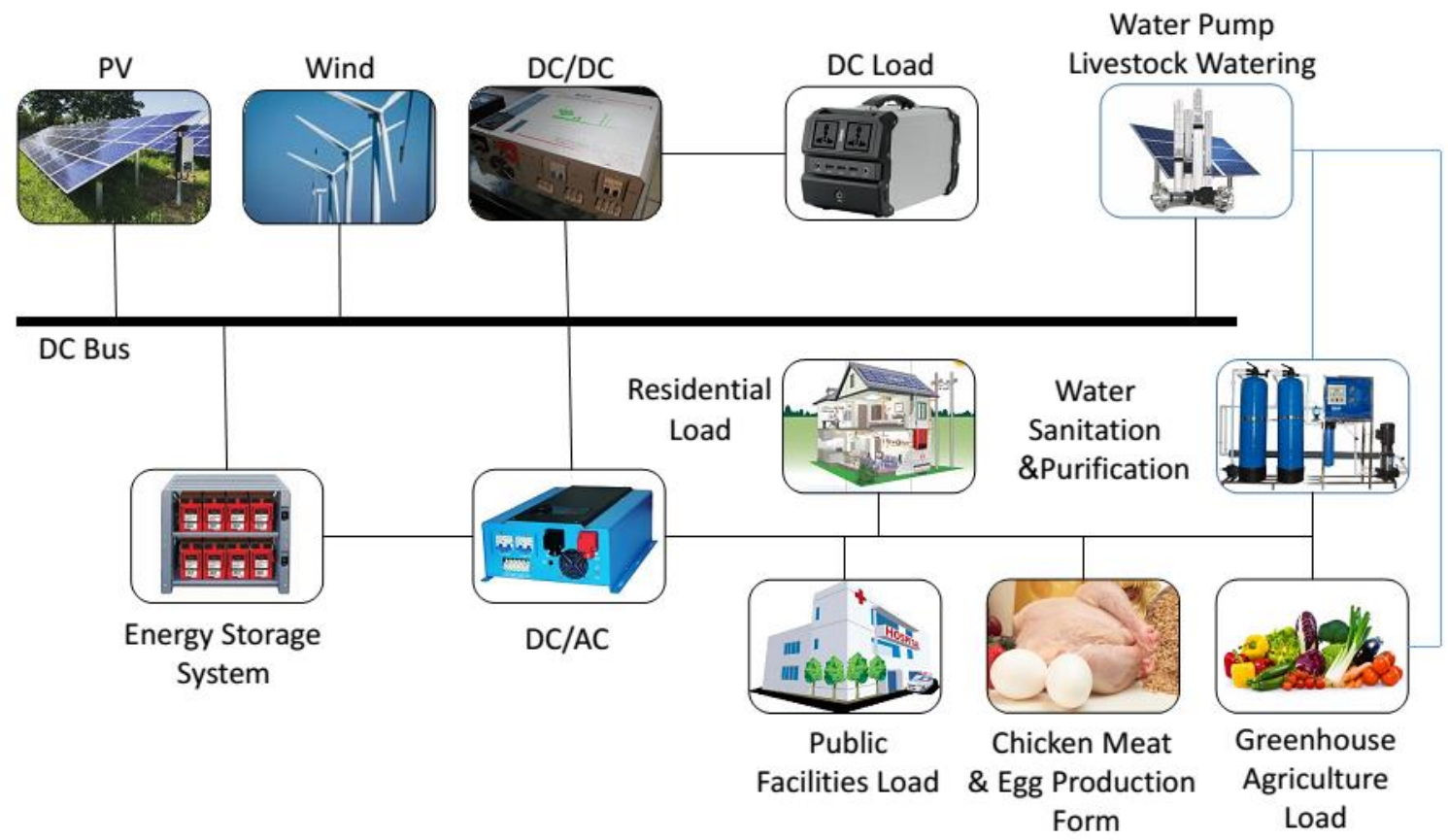

Figure 2. A conceptual electricity and water supply micro-grid model for socio-economic development in Afghanistan

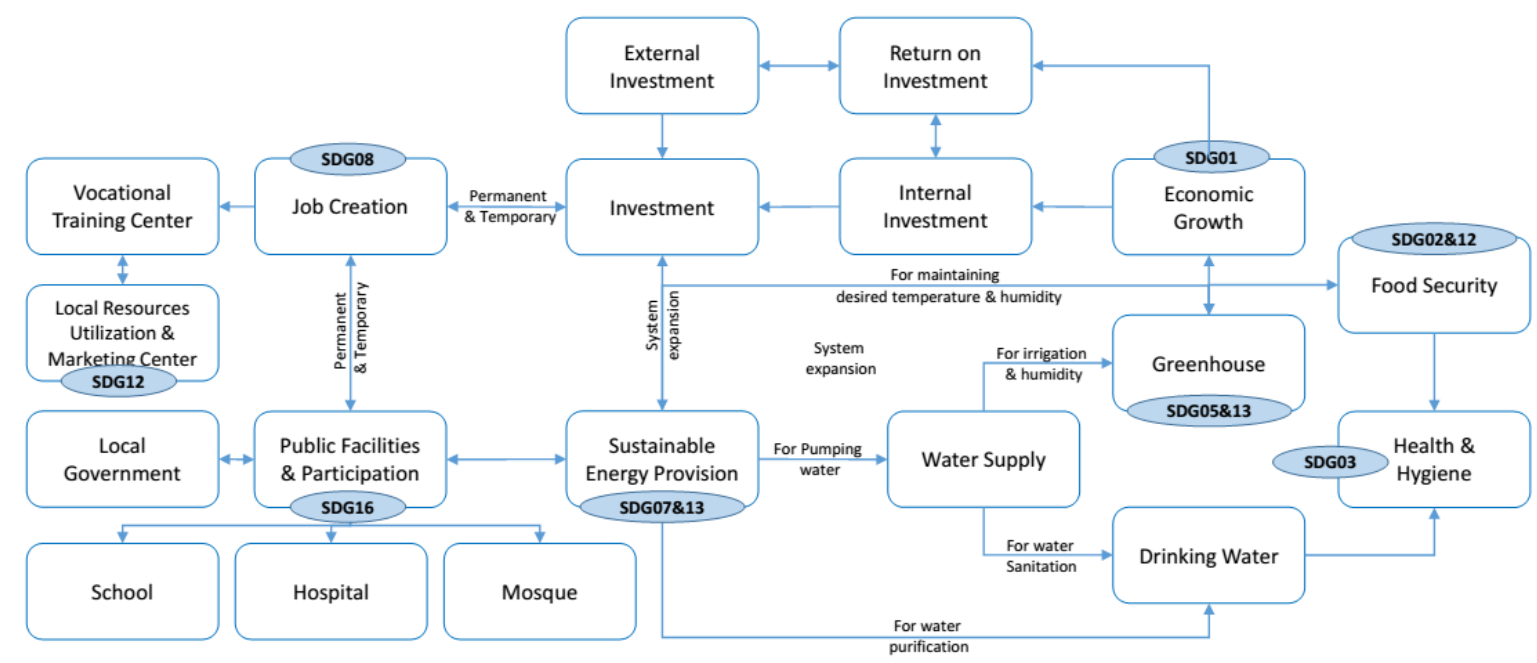

Figure 3. A conceptual scheme for the program lifecycle.

However, details representing the conceptual scheme for the program lifecycle are out of this study scope; local resource utilization as return on investment for self-sufficiency, sustainable human capacity and food security, and lifestyle change are the primary targets. Public awareness, biomass energy utilization in from secondary form of energy, fertilizer technology development, and many more can be the second priority. 
The conceptual scheme for the program lifecycle concentrates on achieving the 2030 SDGs objectives. This scheme tends to attain all the 17 SDGs by using direct and indirect approaches. As it seems in Figure 3, by the perfect deployment of this scheme, 11 SDGs can be achieved directly. The rest of the 6 SDGs can also be achieved to some extends, linked with the direct SDGs. The conceptual scheme of the program management and operation addresses the main millstone, which required a detailed interpretation in terms of program and project management standards (initiation, planning, execution, monitoring, and closure). It seems the implementation of this program will dedicate many resources (human, capital, time, technology, expertise, local participation, etc.) compared to the rest of the program phases (Figure 4).

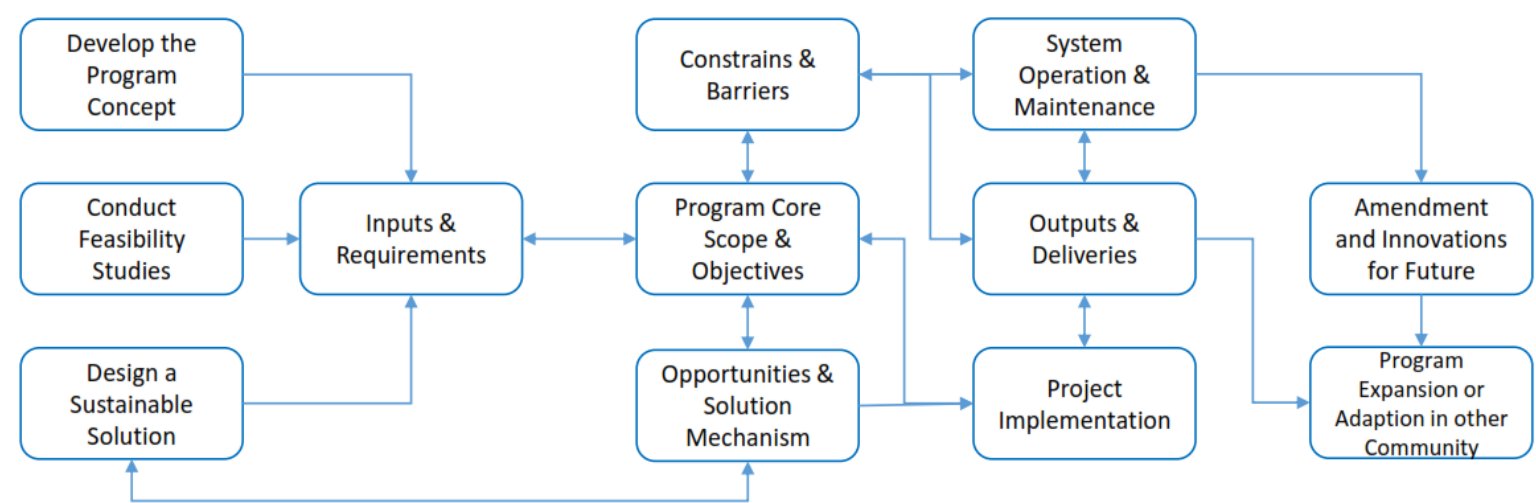

Figure 4. A conceptual scheme of the program management and operation.

Stakeholders' positive engagement at any stage of a program or project adds value to the trends and warrants the successful completion of the program. In this scheme, tentatively, stakeholder's engagements are highlighted. As shown in Figure 4, this study focuses on the primary first element (development of the program concept) of the program management and operation conceptual scheme.

\subsection{Particularities of the proposed mechanism}

The proposed framework demonstrates with some merit that denotes its preference for rural development and achieving the SDGs goals as follows:

- Exhaustivity: In the context of a rural community, this framework deals with all crucial segments for a healthy life.

- Flexibility: The proposed framework can be modified and adapted to the real-life situation from economic, technical, social, and size perspectives.

- Independency: Most likely, the residence is affected by government politics that depends on many factors. At the same time, this concept assures rural independence to government politics and economic transitions that bring self-sufficiency.

- Self-sufficiency: Due to many factors, especially rural distance, rural social and cultural varieties often remain strange from standard services. So, this framework focalized on rural self-sufficiency, considering fortifying factors in assistance this phenomenon.

- In addition, this framework draws a particular jointresearch scheme considering optimum effectuality of the involved parties (international researches institutions and partner country) and Official Development Assistance (ODA).

- Also, it can facilitate joint-researches procedures and methods case by case to ensure proper utilization of the research outcomes and human capacity development within the program timeframe.

\subsection{Adaption of the sustainability pillars in the context of rural communities}

The most important criteria for sustainable energy production and consumption are accessibility, affordability, disparity, safety, use efficiency, supply and production efficiency, cost-effectiveness, and environmental impacts on air, water, and soil quality [16]. The concept of sustainable energy development has been introduced based on these pillars, which are discussed in detail $[17,18]$ :

- Technical sustainability

- Economic sustainability

- Institutional sustainability

- Environmental sustainability

- Social sustainability

\subsubsection{Technical}

As mentioned before, sustainability pillars' adaption can be varying from place to place due to many social, environmental, economic, technical, and institutional reasons. First and foremost, the local resources' investigation must explore the economy of resources, life cycle, and human design. To prosper local resources (human and natural) to 
ensure self-sufficiency, the available primary natural resources need to be transforming to the secondary (useful) form of resources, which needs customized technologies and expertise that can be attained with the help of national and international collaborations. In this regard, the multinational companies (which are a pioneer in any type of industrial and agricultural technologies in the globe) cooperation under the specific program for producing customized and affordable products while providing training would be a great opportunity.

\subsubsection{Environmental}

However, the primary forms of energy resources provide irrefutable benefits for the rural; on the other hand, these resources always accumulate by overloading our atmosphere with greenhouse gas emissions and a steady temperature rise. Therefore, global warming comes into international focus. According to the findings [19], electricity production and consumption emit ten Giga-tones or approximately $37 \%$ of global emissions.

Turning to the recent investigations, the global issues have become increasingly complex and particularly severe in developing countries that cannot be solved by any single country alone. On the planet we live, willingly or unwillingly, we are committed to contributing global esteems to ensure the SDGs and hinder the developing nations' direct and indirect impacts. However, controlling all these impacts would not be possible, but still optimistic about mitigating controllable issues (global warming) and assisting humanity in a severe situation. Global warming will hit poorer countries hardest likely to suffer the biggest increase in hot days and extreme weather because of climate change. Somehow the developing nations play a significant role in global warming due to use of primary energy resources; meanwhile, some reports [20,21] claim that "this is inverse to the generally accepted responsibility for climate change, which falls mainly on rich countries that benefited early on from industry, and thus have historically high emissions, compared with poorer countries that have only begun catching up in the past few decades".

\subsubsection{Economic}

Reference to the reports, localized-standalone services offer a cost-effective alternative to expensive national facilities extension in rural and remote areas of the world. Considering the demography of Afghanistan, predominantly settlements are small and remote, with approximately $78 \%$ of the total population in the rural [22]. An adequate socio-economic model can be feasible for rural Afghanistan in practice to address sufficient needs, fundamental adjustments under the necessity of the present situation.

\subsubsection{Social}

Public participation is a must for every project and program's success, and more importantly, it is for their continued operation for long-run productivity. While reference to the past experience and direct observation from the implemented projects at rural communities, the public participation was not satisfactory. In some cases, public involvement in the rural areas negatively impacted a positive contribution. This intimate that public participation in Afghanistan's rural communities is more complicated than it seems due to many cultural, ideological, and many more factors. So, it can be counted the main reasons behind the failure of most projects in the rural areas of Afghanistan. Just realizing these factors and taking local measures and solutions can be serviceable. Mainly these bottlenecks are due to lack of well-understanding of communities' social and traditional principles.

Due to the importance of public participation, special attention should be paid to this matter. For instance, convincing the communities with a simple but important question might be rise, such as: Why will the program be deployed? What are the aims behind this program? What are the program's short and long terms benefits? Who will govern and keep running this program? Other similar questions may arise and should be answered carefully in their own language and potential (community leaders and influential).

\subsubsection{Institutional}

Investigate energy-related socio-economic sustainability factors and put them forward in energy policy for long-run sustainability, such as community involvement, social acceptability, economic affordability, and equity [23]. The policy and regulation are a principle or a course of action, which it applies to maintain or change the status of targeted scopes. Considering the policy and planning cycle, setting objectives, anticipations costing, implementation and monitoring measures are an elementary part of successful program delivery. Therefore, the institutional pillar is a multi-dimensional endeavor requiring a decent expert team with careful analysis of needs to ensure the program's applicability and long-run sustainability. Developing coherent policies and regulations in light of the SDGs as a benchmark for a customized framework for different communities in different types of requirements (specific area) will accelerate reaching the goals.

\section{Achieving the 2030 global agenda for 17 sustaina- ble development goals (SDGs)}

The 2030 global agenda for 17 SDGs is underlying the broad theme of sustainability, which is put in force to transform the planet and humankind positively by 2030 . These 17 SDGs are poverty alleviation, sustainable food, nutrition, and agriculture, healthy life maintaining, decent and continuous education, gender equality, water sanitation, sustainable energy provision, economic growth, resilient infrastructures, global inequality mitigation, peacefully amicable settlement, enhance moderation between consumption and production, combat climate changes, natural resources, and environmental conservation, protect the ecosystem, socio-economic improvement of the 
societies, and strengthen multinational collaboration and partnership.

Establishing a self-sufficient mechanism based on the repetitive lifecycle of assets can create temporary and permeant jobs to alleviate poverty. Then can follow by food security, nutrition, and agriculture facilities for maintaining a healthy life. Burning wood, leaf, and animal dung traditionally for cooking in rural areas contributes to global warming and accumulates with diseases and solid waste [24]. For this purpose, wide-spreading solar cookers, solar water heaters, solar driers (for harvesting and storing products) will significantly contribute to maintaining a healthy community. Undoubtedly, rural access to crucial life services paves the way for decent education, gender equity, and economic growth that can cause global inequality mitigation, peacefully amicable settlement, and natural resources and environmental conservation.

Microeconomy has been investigated broadly in the literature [20,21,25-27]. One of the newest findings pointed out a micro-level economy paradigm focused on evidence from a home appliance manufacturer [21]. In this study, the implementation of the circular economy at three layers' micro, meso, and macro levels are explored. In another study, the small open economy within a microfounded model is proposed within government bonds [25]. This model deals with technological spillovers from the global economy to the small open economy succeeds in replicating the main macroeconomic and bond pricing. Chad Nilep [20] describes the behavior of four Japanese American individuals and claims that these individuals can adapt to maintain the state's wealth (as micro-economy). Also, this study reveals that the political economy in the fields of linguistic and cultural anthropology has in common with economics. A cross-country comparison study based on the micro-economy analysis is performed in [26]. This study targets three countries Japan, France, and Netherlands from combining firm, industry and country-level. That can provide an in-depth observation of affordable options for micro-economy from different points of view. Paulo N. Figueiredo [27] presents a case study from Brazil on the micro-level technological capability accumulation in developing economies that categorize these capabilities into six groups.

However, the abovementioned micro-economy theorem applications are varied to our scenario. Still, all these studies confirm the effectiveness of micro-economy for long-term sustainability that can be applied to the proposed framework. Overall, agriculture and aviculture farms' on-farm and off-farm applications can be profitable for Afghanistan rural communities' prosperity.

Relying on the agriculture-based economy refers to early in the post-World War 2 with a slogan that "Getting agriculture moving," prerequisites and exigencies [28]:

- Adaptive-productive technologies

- Access to competitive markets
- Storage and warehousing facilities

- Incentive and remunerative programs

Energy security is concerned for a sustainable supply, which defines the accessibility of energy supply at an affordable price in an environmentally friendly atmosphere [17]. Among available theorems, the green economy is an appropriate selection for balancing resource consumption for the purpose of energy provision. This theorem concerns the risk of environmental degradation and resources scarcity and navigating their impacts on national economies [29].

Globally, enormous attention has been paid to switch to renewable energy sources and consider the sustainability dimensions from technological innovation to its implications for greenhouse gas emissions, energy costs reduction, and dependence on technologies with catastrophic potential $[17,30]$. For a rapid economic transformation in rural and remote communities in Afghanistan, among all the effective factors, the below are known salient:

- Rising labor productivity and capacity

- Rural saving mechanism

- Centralized individual income scheme

- Encourage investment at national and local levels

- Maintain capital availability for operation and future expansion

- Individual and centralized community-level saving mechanism

- Innovation programs for productivity and marketing

The proposed mechanism covers the dimensions mentioned above and tries to integrate these factors appropriately. Seriously considering the challenges encounter on our planet, now more than ever before the need for sustainability and transforming the world exists. In addition to all that has been mentioned so far, it can be supposed that this international collaboration between international agencies and local communities can be counted as an opener for Afghanistan's rural and remote communities' self-sufficiency. It can ensure national security, reduce poverty, and combat climate change phenomena that are all part of the global endeavor.

\section{Contributions of the study}

In the last two decades, many projects are implemented throughout Afghanistan for rural communities' empowerment with limited short-term revenue. The implemented projects demonstrate with number of deficiencies from different standpoints. However, considering the Afghanistan situation during the past two decades would not be anticipated a perfect outcome from these projects. At the main while, there have been number of controllable factors to avoid significant shortcomings. These factors mainly refer to the lack of proper coordination among sectorial organizations were responsible for rural 
development and the lack of proper management of project implementation and operation.

The proposed framework tries to deal with the causative factors that affect a rural project implementation and operation for long-run sustainability from the lessons learned. Separately the identified factors such as lack of the risk management plan for the entire project period and beyond this period, supportive plans for maintenance and operation, self-sufficiency plans for keeping continue the services as well as to expand the services by communities themselves, and creating close coordination among involved parties (local government, leaders, experts, beneficiaries, etc.) are investigated. In the past, implemented projects have had focused on a specific target within limited outcomes. At the same time, this study explores a rural community all essential segments such as twenty-fourhour electricity supply, drinking water, local food, agriculture, capacity building, self-sufficiency, etc. Deployment of this framework will obliterate the monopolist culture that a unique organization controls all the projects with limited knowledge and expertise. In the proposed framework, research, implementation, supervision, controlling and monitoring, infestation, and future innovation layers are based on the multi-expertise engagement to assure a sufficient service.

\section{Anticipated outcomes in brief}

Given figures and information in Table 1, indicate a rough approximation due to the nature of communities, real situation, the area of application, etc. That can vary case by case and community to community. The present status of a moderate community is a benchmark for anticipated improvement, obtained from direct observation and face-toface interviews with the residents of these communities. As mentioned earlier, for proper deployment of a program aligned with the SDGs, a customized solution for every community should be considered within a specific benchmark (the general developed concept).

Table 1: The anticipated outcomes from the proposed framework confirming the SDGs.

\begin{tabular}{|c|c|c|c|c|c|}
\hline \multicolumn{2}{|c|}{ SDGs } & \multicolumn{3}{|c|}{$\begin{array}{l}\text { The SDGs applicabil- } \\
\text { ity in the proposed } \\
\text { conceptual frame- } \\
\text { work (a very rough } \\
\text { approximation) }\end{array}$} & \multirow[b]{2}{*}{ Expected outcome (within the first five tears of the pilot project) } \\
\hline No. & Descriptions & 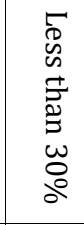 & 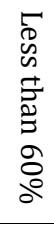 & 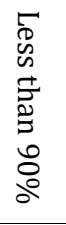 & \\
\hline 1 & Poverty alleviation: & & & O & $\begin{array}{l}\text { It is expected to be a dramatic increase in residence income per capita } \\
\text { (especially young students, illiterates, and women) to a level of 55-75\%. }\end{array}$ \\
\hline 2 & $\begin{array}{l}\text { Sustainable food, nutrition, } \\
\text { and agriculture }\end{array}$ & & O & & $\begin{array}{l}\text { Due to enough land availability and local constraints, it is expected to } \\
\text { reach a target of up to } 60 \% \text {. }\end{array}$ \\
\hline 3 & Healthy life maintaining & & $\mathrm{O}$ & & $\begin{array}{l}\text { For Afghanistan's communities, this target is much dependent on culture } \\
\text { and mores than facilities and possibly. So, maintaining lifestyle change } \\
\text { can be expected under } 35 \% \text {. }\end{array}$ \\
\hline 4 & $\begin{array}{l}\text { Decent and continues educa- } \\
\text { tion }\end{array}$ & & O & & $\begin{array}{l}\text { Considering positive attitude toward a rapid acceptance rate of new tech- } \\
\text { nologies in the recent years, the decent and continuous education rate } \\
\text { can be anticipated between } 45-55 \% \text {. }\end{array}$ \\
\hline 5 & Gender equality & O & & & $\begin{array}{l}\text { Local settlement availability, easy access to the work field, determined } \\
\text { individual significance and outcomes; will bring gender equality in the } \\
\text { long term. }\end{array}$ \\
\hline 6 & Water sanitation & & & O & $\begin{array}{l}\text { By deploying the proposed program, access to clean and healthy water } \\
\text { for drinking will reach more than } 80 \% \text {. }\end{array}$ \\
\hline 7 & Sustainable energy provision & & & $\bigcirc$ & $\begin{array}{l}\text { Rural energy consumption culture for the basic needs of electricity and } \\
\text { other types of energy, within five years, the sustainable energy supply } \\
\text { rate will reach nearly } 70 \% \text {. }\end{array}$ \\
\hline 8 & Economic growth & & & $\mathrm{O}$ & Roughly between $65-80 \%$ \\
\hline 9 & Resilient infrastructures & O & & & $\begin{array}{l}\text { Due to the lack of even basic infrastructures in some rural communities, } \\
\text { this goal should not be achievable as much as expected. }\end{array}$ \\
\hline 10 & Global inequality mitigation & O & & & $\begin{array}{l}\text { Considering the scale of this program compared to the global equality } \\
\text { criteria and targets, the proposed program within medium-term of five } \\
\text { years may not contribute to this trend. }\end{array}$ \\
\hline 11 & Peacefully amicable settlement & & & O & $\begin{array}{l}\text { Most of the rural communities are involved in agriculture and livestock } \\
\text { affairs. This program will help them ensure their job security by creating } \\
\text { new permanent jobs in modern agriculture (greenhouse) and aviculture } \\
\text { farms. }\end{array}$ \\
\hline
\end{tabular}




\begin{tabular}{|c|c|c|c|c|}
\hline 12 & $\begin{array}{l}\text { Enhance moderation between } \\
\text { consumption and production }\end{array}$ & & O & $\begin{array}{l}\text { Still, life expectancy remains low in rural communities in Afghanistan; } \\
\text { the proposed program would be more than enough to balance local con- } \\
\text { sumption with production within a specific timeframe. }\end{array}$ \\
\hline 13 & Combat climate changes & & $\mathrm{O}$ & $\begin{array}{l}\text { The primary resource of greenhouse gas emissions in rural communities } \\
\text { is the use of primary resources of energy. More than expected, this goal is } \\
\text { achievable by implementing this program and providing the secondary } \\
\text { form of energy (clean and green). }\end{array}$ \\
\hline 14 & $\begin{array}{l}\text { Natural resources and envi- } \\
\text { ronment conservation }\end{array}$ & O & & $\begin{array}{l}\text { This matter is turning to Goal 13. By accessing clean and sustainable en- } \\
\text { ergy, the rate of demolishing forests and natural environments would be } \\
\text { significantly reduced. }\end{array}$ \\
\hline 15 & Protect the ecosystem & O & & $\begin{array}{l}\text { This goal is somehow linked to all the previous goals, so this goal is } \\
\text { achievable by maintaining the abovementioned goals. }\end{array}$ \\
\hline 16 & $\begin{array}{l}\text { Socio-economic improvement } \\
\text { of the societies }\end{array}$ & $\mathrm{O}$ & & $\begin{array}{l}\text { This goal comprises two segments of social and economic. The economic } \\
\text { aspects are more manageable, while the social aspects are turning to } \\
\text { some complicated indicators that will not be changeable within the life of } \\
\text { this program. }\end{array}$ \\
\hline 17 & $\begin{array}{l}\text { Strengthen multinational col- } \\
\text { laboration and partnership }\end{array}$ & & $\mathrm{O}$ & Initiating such programs will contribute to international collaborations. \\
\hline
\end{tabular}

\section{Conclusion}

This study roughly outlined a framework to be more explored in feasibility studies and conceptualization for rural sustainability in Afghanistan. This study is designed as a general objective-oriented. It is prospected to interpret this study in a detailed technical and theoretical proposal for a pilot project. In addition to the technical and economic feasibility assessments, the research and model development stage will deal with a broad theme of studying the boundaries, constraints, opportunities, and challenges at the communities level; to define adequate thresholds of the population concentration in the communities, communities categorization, economic growth indicators, human capacity development measures, self-independency and lifestyle changes indices, and finally to set up scalable measures for climate change and poverty mitigation near to the fact.

The proposed framework aims to improve the quality of life in rural communities in Afghanistan, meet their indispensable daily expectations, motivate locals for self-sufficiency for long-run sustainability, maintain a peaceful environment, reduce greenhouse gases emissions, and preserve the natural environment. That directly can achieve the SDG 2030 goals. A multi-collaboration commitment is inherent to warrant the sustainability of this trend for a long-term operation and innovation. This commitment can reaffirm by intergovernmental, national and international elites at national and local levels.

\section{Acknowledgment}

This publication resulted (in part) from research conducted under the Academic Exchange Collaboration Agreement between Faculties of Engineering, Kabul University (Kabul, Afghanistan), and University of the Ryukyus (Okinawa, Japan) signed on 15 December 2020.

\section{References}

[1] The science and technology research partnership for sustainable development (SATREPS) project outcomes for the 2030 sustainable development goals (SDGs) (2018) Tokyo, Japan, Japan Science and Technology Agency (JST). (https://www.jst.go.jp/global/english/public/shiryo/re_satreps_eng.pdf) Accessed: 17 July 2019

[2] Danish MSS, Sabory NR, Danish SMS, Ludin GA, Yona A, et al. (2016) "An Open-door Immature Policy for Rural Electrification: A Case Study of Afghanistan" International Journal of Sustainable and Green Energy (vol. 6, no. 3, pp. 8-13) https://doi.org/10.11648/j.ijrse.s.2017060301.12

[3] Danish MSS, Yona A, Senjyu T (2014) "Pre-design and life cycle cost analysis of a hybrid power system for rural and remote communities in Afghanistan" The Journal of Engineering-IET (vol. 2014, no. 8, pp. 438-444) https://doi.org/10.1049/joe.2014.0172

[4] Sediqi A (2010) "A preliminary assessment of air quality in Kabul" Kabul, Afghanistan, Ministry of Mines. (https://www.afghan-web.com/docs/kabul_air_quality.pdf)

[5] Danish MSS, Zaheb H, Sabory NR, Karimy H, Faiq AB, et al. (2019) "The Road Ahead for Municipal Solid Waste Management in the 21st Century: A Novel-standardized Simulated Paradigm" IOP Conference Series: Earth and Environmental Science IOP Publishing, vol. 291 - pp. 1-5. https://doi.org/10.1088/1755-1315/291/1/012009

[6] The Paris Agreement (2018) United Naitons: Climate Change (https://unfccc.int/process-and-meetings/theparis-agreement/the-paris-agreement) Accessed: 17 July 2019

[7] United Nations Treaty Collection: Environemnt (2015) Paris, France. (https://treaties.un.org/Pages/ViewDetails.aspx?src=IND\&mtdsg_no= XXVII-7-d\&chapter=27\&clang=_en) Accessed: 17 July 2019

[8] 1461693282115-WS-Afghanistan-sign (https://treaties.un.org/doc/Treaties/2016/02/20160215\%2006-03\%20PM/Actions/1461693282115-WS-Afghanistan-sign.jpg) Accessed: 22 July 2021 
[9] Danish MSS, Sabory NR, Ershad AM, Danish SMS, Ohta R, et al. (2017) "The Least Developed Countries Need for Changing the Passive Trend of Renewable Energy Exploitation to a Proactive Trend" International Journal of Energy and Power Engineering (vol. 5, no. 6, pp. 215-221) https://doi.org/10.11648/j.ijepe.20160506.17

[10] Waas T, Hugé J, Block T, Wright T, Benitez-Capistros F, et al. (2014) "Sustainability Assessment and Indicators: Tools in a Decision-Making Strategy for Sustainable Development" Sustainability (vol. 6, no. 9, pp. 5512-5534) https://doi.org/10.3390/su6095512

[11] Brenna M, Falvo MC, Foiadelli F, Martirano L, Poli D (2012) "Sustainable Energy Microsystem (SEM): preliminary energy analysis" 2012 IEEE PES Innovative Smart Grid Technologies (ISGT) Washington, DC, USA, IEEE - pp. 1-6. https://doi.org/10.1109/ISGT.2012.6175735 (http://ieeexplore.ieee.org/document/6175735/) Accessed: 3 February 2019

[12] Liu M (Max), Mi B (2017) "Life cycle cost analysis of energyefficient buildings subjected to earthquakes" Energy and Buildings (vol. 154, pp. 581-589) https://doi.org/10.1016/j.enbuild.2017.08.056

[13] Corral L, Reardon T (2001) "Rural Nonfarm Incomes in Nicaragua" World Development (vol. 29, no. 3, pp. 427-442) https://doi.org/10.1016/S0305-750X(00)00109-1

[14] Coeymans J, Mundlak Y (1993) "Sectoral growth in Chile: 1962-82" Research reports International Food Policy Research Institute (IFPRI). (https://econpapers.repec.org/paper/fprresrep/95.htm) Accessed: 23 July 2021

[15] Poornachandra Rao GVS, Bhalla MS (1981) "Palaeomagnetism of Dhar traps and drift of the subcontinent during the Deccan volcanism" Geophysical Journal International (vol. 65, no. 1, pp. 155-164) https://doi.org/10.1111/j.1365-246X.1981.tb02705.x

[16] Danish MSS, Senjyu T, Sabory NR, Danish SMS, Ludin GA, et al. (2017) "Afghanistan's aspirations for energy independence: Water resources and hydropower energy" Renewable Energy (vol. 113, pp. 1276-1287) https://doi.org/10.1016/j.renene.2017.06.090

[17] Danish MSS, Sabory NR, Ershad AM, Danish SMS, Yona A, et al. (2016) "Sustainable Architecture and Urban Planning trough Exploitation of Renewable Energy" International Journal of Sustainable and Green Energy (vol. 6, no. 3, pp. 1) https://doi.org/10.11648/j.ijrse.s.2017060301.11

[18] Frame D, Tembo K, Dolan MJ, Strachan SM, Ault GW (2011) "A community based approach for sustainable off-grid PV systems in developing countries" 2011 IEEE Power and Energy Society General Meeting Detroit, MI, USA, IEEE - pp. 17. $\quad$ https://doi.org/10.1109/PES.2011.6039593 (http://ieeexplore.ieee.org/document/6039593/) Accessed: 3 February 2019
[19] Cucchiella F, D’Adamo I, Gastaldi M, Koh SL, Rosa P (2017) "A comparison of environmental and energetic perfor mance of European countries: A sustainability index" Renewable and Sustainable Energy Reviews (vol. 78, pp. 401413) https://doi.org/10.1016/j.rser.2017.04.077

[20] Nilep C (2009) "Sibling interaction and symbolic capital: Toward a theory of political micro-economy" Journal of Pragmatics (vol. 41, no. 9, pp. 1683-1692) https://doi.org/10.1016/j.pragma.2009.02.005

[21] Cleaner production as an antecedent for circular economy paradigm shift at the micro-level: Evidence from a home appliance manufacturer (2018) Journal of Cleaner Production (vol. 185, pp. 740-748) https://doi.org/10.1016/j.jclepro.2018.03.006

[22] Burns RK (2011) "Afghanistan: Solar assets, electricity production, and rural energy factors" Renewable and Sustainable Energy Reviews (vol. 15, no. 4, pp. 2144-2148) https://doi.org/10.1016/j.rser.2010.12.002

[23] Rosen MA (2009) “Energy Sustainability: A Pragmatic Approach and Illustrations" Sustainability (vol. 1, no. 1, pp. 55-80) https://doi.org/10.3390/su1010055

[24] Danish MSS, Senjyu T, Zaheb H, Sabory NR, Ibrahimi AM, et al. (2019) "A novel transdisciplinary paradigm for municipal solid waste to energy" Journal of Cleaner Production (vol. 233, pp. 880-892)

[25] Ilek A, Rozenshtrom I (2018) "The term premium in a small open economy: A micro-founded approach" International Review of Economics \& Finance (vol. 57, pp. 333-352) https://doi.org/10.1016/j.iref.2018.02.002

[26] Dobbelaere S, Kozo K, Mairesse J (2012) “Product and Labor Market Imperfections and Scale Economies: Micro-evidence on France, Japan and the Netherlands" CREST (ParisTech-ENSAE), UNU-MERIT (Maastricht University) and National Bureau of Economic Research (NBER) (pp. 26)

[27] Figueiredo PN (2017) "Micro-level technological capability accumulation in developing economies: Insights from the Brazilian sugarcane ethanol industry" Journal of Cleaner Production (vol. 167, pp. 416-431) https://doi.org/10.1016/j.jclepro.2017.08.201

[28] Gardner BL (2005) "Causes of rural economic development" Agricultural Economics (vol. 32, no. s1, pp. 21-41) https://doi.org/10.1111/j.0169-5150.2004.00012.x

[29] Luederitz C, Abson DJ, Audet R, Lang DJ (2017) “Many pathways toward sustainability: Not conflict but co-learning between transition narratives" Sustainability Science (vol. 12, no. 3, pp. 393-407) https://doi.org/10.1007/s11625-0160414-0

[30] Kostyk T, Andrews CJ, Herkert J, Miller C (2011) “Energy and society: challenges ahead" 2011 IEEE International Symposium on Technology and Society (ISTAS) pp. 1-1. https://doi.org/10.1109/ISTAS.2011.7160603 